\title{
Pes Planus Foot among the First and Second Year Medical Students of a Medical College: A Descriptive Cross-sectional Study
}

\author{
Diwakar Kumar Shah, ${ }^{1}$ Sanzida Khatun' \\ 'Department of Anatomy, Nobel Medical College and Teaching Hospital, Biratnagar, Nepal.
}

Introduction: Foot is a complex segmented structure formed by the articulation of 26 different bones which are held together by multiple ligaments, extrinsic tendons and the intrinsic muscles of the feet. The assessment of median longitudinal arch serves as an important reference in determining the degree of pes planus or pes cavus. This study aims to find the prevalence of pes planus among the undergraduate medical students of a medical college.

Methods: A descriptive cross-sectional study was carried out in the first- and second-year undergraduate medical students of a teaching hospital after taking ethical approval from Institutional Review Committee. The study was conducted from 15th November 2019 to 14th November 2020. Eighty-seven participants were involved in study using the random sampling technique. Foot prints were collected from the participants in the A4 size paper after applying ink over plantar surface of the foot. Measurements were done using the Autodesk Autocad software. Statistical Package for the Social Sciences was used. Point estimate at 95\% Confidence Interval was calculated along with frequency and proportion for binary data.

Results: Out of the total subjects, 14 (8.04\%) (5.14-10.94 at 95\% Confidence Interval) presented with flat foot. Similarly, high arched foot was seen in 29 (16.67\%) of subjects whereas normal arched foot was seen in $131(75.29 \%)$ subjects.

Conclusions: From the current study we conclude that the prevalence of pes planus was slightly higher than that compared with the similar studies.

Keywords: foot; foot print; pes cavus; pes planus; sole.

\section{INTRODUCTION}

Foot is a complex segmented structure formed by the articulation of 26 different bones held together by multiple ligaments. ${ }^{1}$ The skeleton of foot is arched in such a way that both longitudinal and transverse arches are formed within the foot with the concavity directed towards the plantar surface of the foot. ${ }^{2}$ Pes planus (flat foot) and pes cavus (high arched foot) are the most frequently seen foot problems. ${ }^{3}$ These conditions can by determined by assessment of median longitudinal arch (MLA).

Not much of attention is given to the foot health status in the developing countries like Nepal. Studies have shown that the injuries pattern may vary upon the type of foot arch. ${ }^{4}$ Hardly a couple of studies have been conducted in Nepal regarding the foot arches.
Hence, the present study aims to determine the prevalence of Pes Planus in the undergraduate medical students of Nobel Medical College, Biratnagar.

\section{METHODS}

A descriptive cross-sectional study was carried out in the undergraduate medical students of $1^{\text {st }}$ and $2^{\text {nd }}$ year of Nobel Medical College, Biratnagar. The study was conducted from $15^{\text {th }}$ November 2019 to $14^{\text {th }}$ November 2020.

Ethical approval was taken prior to beginning the study from the Institutional Review Committee Nobel

Correspondence: Dr. Diwakar Kumar Shah, Department of Anatomy, Nobel Medical College and Teaching Hospital, Biratnagar, Nepal. Email: dwkrshah21@gmail.com, Phone: +977. 9852029842 . 
Medical College. Written consent was obtained from all the participants involved in the study. Roy $\mathrm{H}$ et al from their study reported that the prevalence of flat foot was $4.9 \% .^{5}$ Using the formula,

$$
\begin{aligned}
\mathrm{n} & =\mathrm{Z}^{2} \times \mathrm{p} \times \mathrm{q} / \mathrm{e}^{2} \\
& =(1.96)^{2} \times 4.9 \times(1-4.9) /(0.05)^{2} \\
& =74
\end{aligned}
$$

where,

$\mathrm{n}=$ required sample size,

$\mathrm{Z}=\mathbf{1 . 9 6}$ at $95 \%$ Confidence Interval (CI)

$\mathrm{p}=$ prevalence of pes planus, $4.9 \%^{5}$

$q=1-p$

$\mathrm{e}=$ margin of error, $5 \%$

Thus, a total of 87 participants were involved in the study following the random sampling technique.

Foot prints were collected from the participants in the A4 size paper after applying ink over the plantar surface of the foot. To reduce the errors due to distortion while scanning the images of the foot prints, a $5 \mathrm{~cm}$ line was drawn at the corner of the page. Measurements were done using the Autodesk AutoCAD software 2020.

Foot axis was drawn from the center of the heel to the tip of the 2 nd toe and then the foot print was divided into three equal thirds excluding the toes. Using the Autodesk AutoCAD software 2020 the areas of A, B \& C were calculated and then the arch index was calculated for the individual foot using the formula

$\mathrm{Al}=\mathrm{B} / \mathrm{A}+\mathrm{B}+\mathrm{C}$

Where $A$ is the area of the forefoot, $B$ is the area of midfoot and $C$ is the area of the heel region of the foot.

Al scores were then used to classify the foot prints into three different categories: high $(\leq 0.21)$, normal $(0.21$ to $0.28)$, low $(\geq 0.28){ }^{6}$

Subjects who were not known to any foot disease or deformities were included in the study.

Subjects who have undergone any foot surgeries or who are known cases of any foot disease were excluded from the study.

Statistical Package for the Social Sciences software was used for the data analysis. Point estimate at 95\% Confidence Interval was calculated along with frequency and proportion for binary data.
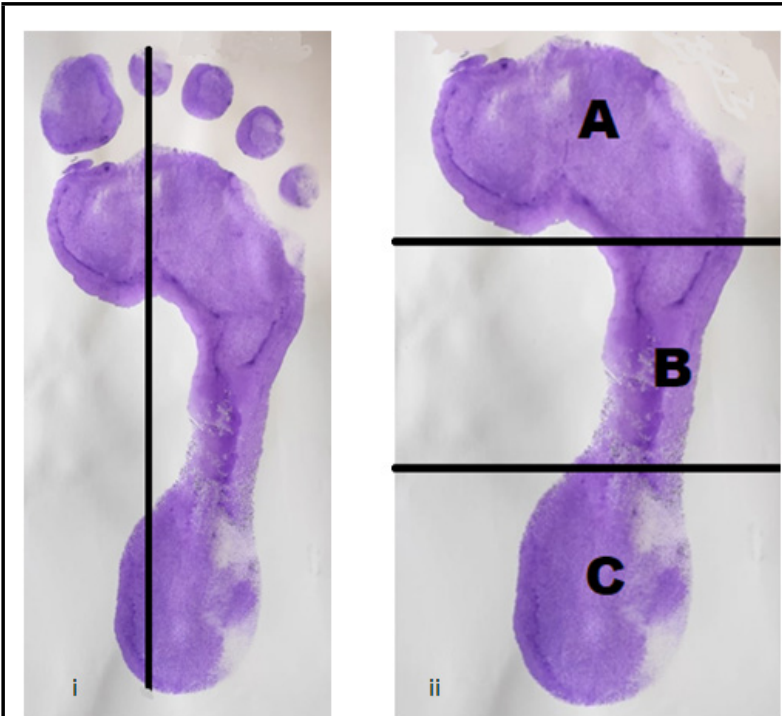

Figure 1. (i) Showing foot print of right foot with its central axis passing from the heel to the 2 nd toe. (ii) Showing the area of Fore foot (A), Mid foot (B) and Heel region (C) of the foot.

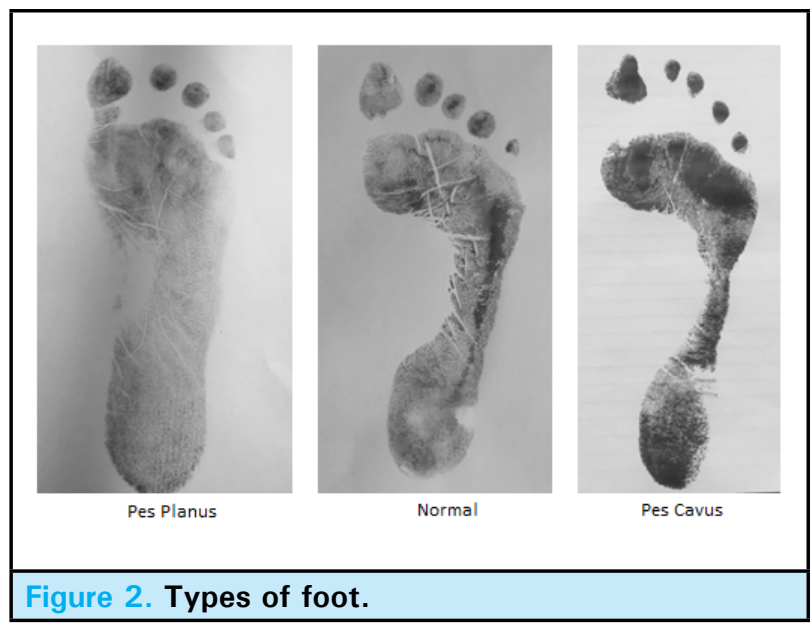

\section{RESULTS}

Out of total participants, prevalence of Pes Planus 14 (8.04\%) (5.14-10.94 at 95\% Cl) where as 131 (75.29\%) had normal arched foot and $29(16.67 \%)$ of the subjects had high arched foot (Pes Cavus).

High arched foot was seen in 17 (19.77\%) of female subjects and 11 (13.64\%) of males. High arched foot was seen in the right foot in $12(13.79 \%)$ of cases and $19.54 \%$ in the left foot. Only $8.04 \%$ of the subjects were identified with flat foot (Pes Planus) out of which $2(2.27 \%)$ were male subjects and $12(13.95 \%)$ were female subjects. Most of the subjects were identified with flat foot on the right side (10.34\%).

Eighty-seven participants were involved in the study out of which 43 were females $(49.4 \%)$ and 44 were males $(50.6 \%)$. 
Shah et al. Pes Planus Foot among First- and Second-year Medical Students of a Medical College...

\begin{tabular}{|llllllll|}
\hline \multicolumn{7}{|l}{ Table 1. Frequency of different foot types in male and female subjects. } \\
\hline & $\begin{array}{l}\text { Pes Cavus } \\
\text { Left Foot } \\
\mathbf{n}(\%)\end{array}$ & $\begin{array}{l}\text { Right Foot } \\
\mathbf{n}(\%)\end{array}$ & $\begin{array}{l}\text { Left Foot } \\
\mathbf{n}(\%)\end{array}$ & $\begin{array}{l}\text { Right Foot } \\
\mathbf{n}(\%)\end{array}$ & $\begin{array}{l}\text { Pes Planus } \\
\text { Left Foot } \\
\mathbf{n}(\%)\end{array}$ & $\begin{array}{l}\text { Right Foot } \\
\mathbf{n}(\%)\end{array}$ \\
$\begin{array}{l}\text { Female } \\
\mathbf{n}(\%)\end{array}$ & $9(52.94)$ & $8(66.667)$ & $30(46.15)$ & $27(40.9)$ & $4(80)$ & $8(88.89)$ & $86(49.42)$ \\
$\begin{array}{l}\text { Male } \\
\mathbf{n}(\%)\end{array}$ & $8(47.05)$ & $4(33.33)$ & $35(53.84)$ & $39(59.09)$ & $1(20)$ & $1(11.11)$ & $88(50.57)$ \\
Total & 17 & 12 & 65 & 66 & 5 & 9 & 174 \\
\hline
\end{tabular}

\begin{tabular}{|c|c|c|}
\hline Foot Type & Male n (\%) & Female n (\%) \\
\hline Normal & 74 (84.09) & $57(66.28)$ \\
\hline Pes Planus & $2(2.27)$ & $12(13.95)$ \\
\hline Pes Cavus & $12(13.64)$ & $17(19.77)$ \\
\hline Total & $88(100)$ & $86(100)$ \\
\hline
\end{tabular}

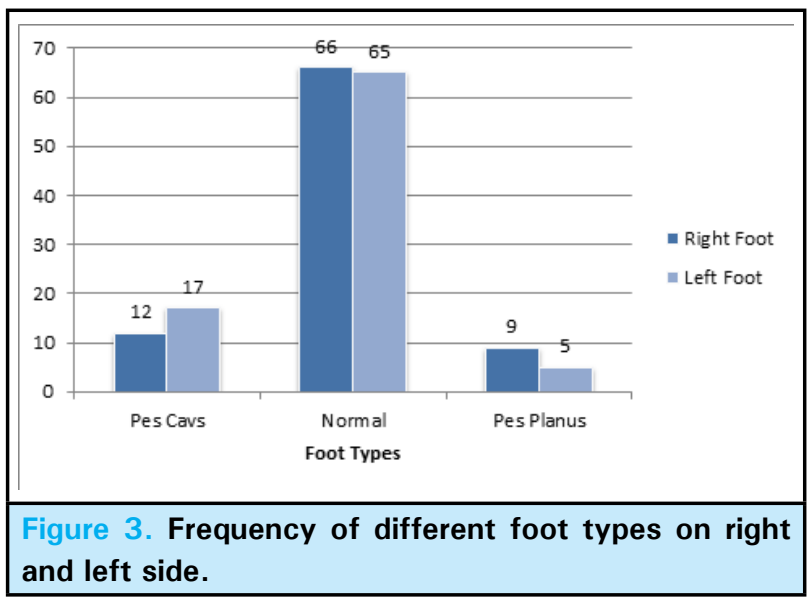

\section{DISCUSSION}

Medial longitudinal arch remains the major component affecting the functions of the foot. For proper diagnosis and appropriate decision making regarding the reconstructive surgeries, evaluation of the foot arch remains the major component. ${ }^{3}$ Analysis of the foot prints for the evaluation of foot arch is the most popular technique due to its simplicity and reproducibility. ${ }^{7}$

The objective of the study was to determine the prevalence of pes planus in the Undergraduate Medical students of Nobel Medical College.

From the present study we found that flat foot was present in $8.04 \%$ of subjects. The results were similar and comparable to the results of many authors who from their respective studies reported $5.1 \%, 11.25 \%$, $10 \%, 13.6 \% 0,16.1 \%$ prevalence of pes planus. ${ }^{4,8-11}$

Vangara SM, et al. from their study reported that the overall prevalence of pes planus was $26.4 \%$ and $25.6 \%$ for right and left foot respectively. ${ }^{1}$ Another study done in Nigerian children by Ezema $\mathrm{Cl}$, et al. reported the prevalence of flat foot in $22.4 \%$ of subjects. ${ }^{12} \mathrm{~A}$ study carried on the Iranian students showed a very high incidence of flat foot i.e $74 \% .{ }^{13}$ A Srilankan study reported the incidence of flat foot in $51.6 \%$ of subjects. ${ }^{14}$ These results were comparatively much higher than what we found from the present study.

We also found that $16.67 \%$ of the total subjects examined showed high arched foot. The findings were quite comparable with the findings of a similar study carried by Kharbuja R, et al. in the children of Bhaktapur district where they found that the high arched foot was present in $25.5 \%$ and $17.8 \%$ of subjects in the right and the left foot respectively. ${ }^{4}$

Pes planus may be a result of tarsal coalition, disruption of tendon of tibialis posterior, rupture of spring ligament, tarsometatarsal arthritis and hind foot degeneration or inflammatory arthritis. ${ }^{15}$

Erol K, et al. from their study reported that the Posterior Tibial tendon dysfunction (PTTF) remains a very important cause of Pes Planus. ${ }^{16}$ Apley AG in his article regarding the flat foot mentioned the anatomical and physiological causes of Pes Planus. He mentioned that the bony arch of foot is potentially unstable, bound by ligaments and is capable of resisting short term stress only. He stated that poor nervous control, inadequate muscles and infections may also cause flat foot. ${ }^{17}$

Vangara SV, et al. from their study reported that the incidence of Pes Cavus was 58.9\% and $66.7 \%$ for the right and the left foot respectively which was very much high when compared to results from the current study. ${ }^{1}$

Pes cavus may arise due to some neurological disorder such as Charcot-Marie-Tooth disease, diastematomyelia, poliomyelitis etc. ${ }^{15}$

A large sample size can be taken in order to see the prevalence of flat foot among the Nepalese population followed by the clinical evaluation in order to establish the cause of flat foot and accordingly plan for the possible remedies/treatment for its correction. 
Shah et al. Pes Planus Foot among First- and Second-year Medical Students of a Medical College...

\section{CONCLUSIONS}

From the current study we conclude that the prevalence of pes planus was slightly higher than that compared with the similar studies.

\section{ACKNOWLEDGEMENTS}

We would like to thank Ar. Muskan Bhakta for helping us with the measurements and calculations of areas of foot using the Autodesk AutoCAD software 2020.

\section{REFERENCES}

1. Vangara SV, Gopichand PV, Bedi M, Puri N. Effect of barefoot walking on foot arch structure in Tribal children. Asian Journal of Medical Sciences. 2016 Aug 31;7(5):108-16. [Full Text | DOI]

2. Singh V. Textbook of Anatomy: Abdomen and Lower Limb. 2nd ed. Faridabad: Elsevier; 2014.p. 432. [Full Text]

3. Yalçin N, Esen E, Kanatli U, Yetkin H. Evaluation of the medial longitudinal arch: a comparison between the dynamic plantar pressure measurement system and radiographic analysis. Acta Orthop Traumatol Turc. 2010 Jan 1;44(3):241-5. [PubMed | DOI]

4. Kharbuja R, Dhungel S. Prevalence Of Pes Cavus And Pes Planus Among School Going Children Of Bhaktapur District, Nepal. Nepal Med Coll J. 2017;19(1):9-12. [Full Text]

5. Roy H, Bhattacharya K, Deb S, Ray K. Arch index: an easier approach for arch height (a regression analysis). Al Ameen Journal of Medical Sciences. 2012;5(2):137-46. [Full Text]

6. Menz HB, Fotoohabadi MR, Wee E, Spink MJ. Visual categorisation of the arch index: a simplified measure of foot posture in older people. Journal of foot and ankle research. 2012 Dec;5(1):1-7. [Full Text | DOI]

7. Cavanagh PR, Rodgers MM. The arch index: a useful measure from footprints. J Biomech 1987; 20:547-51. [uㅏMed | DOI]

8. Bhoir MT. Prevalence of flat foot among 18-25 years old physiotherapy students: cross sectional study. [Full Text]

9. Rithanya P, Babu KY, Mohanraj KG. Assessment of flat foot by plantar arch index using footprint in aged population. Drug Invention Today. 2018 Nov 1;10(11). [․ull Text]

10. Aenumulapalli A, Kulkarni MM, Gandotra AR. Prevalence of flexible flat foot in adults: A cross-sectional study. J. Clin
Diagn Res. JCDR. 2017 Jun;11(6):AC17-AC20. [PubMed | Full Text | DOI]

11. Pourghasem M, Kamali N, Farsi M, Soltanpour N. Prevalence of flatfoot among school students and its relationship with BMI. Acta orthopaedica et traumatologica turcica. 2016 Oct 1;50(5):554-7. [ubMed | Full Text | DOI]

12. Ezema CI, Abaraogu UO, Okafor GO. Flat foot and associated factors among primary school children: A cross-sectional study. Hong Kong Physiotherapy Journal. 2014 Jun 1;32(1):13-20. [Full Text | DOI]

13. Askary Kachoosangy R, Aliabadi F, Ghorbani M. Prevalence of flat foot: comparison between male and female primary school students. Iranian Rehabilitation Journal. 2013 Oct 10;11(3):22-4. [Full Text]

14. Samarakoon JN, de Silva NL, Fernando D. Prevalence and Associated Factors of Flat Feet among Patients with Hypertension; Findings from a Cross Sectional Study Carried Out at a Tertiary Care Hospital in Sri Lanka. Archives of Physiotherapy and Rehabilitation. 2020;3(4):76-83. [Full Text]

15. Mahadevan V. Pelvic Girdle and Lower Limb. In: S. Standring, ed., GRAY'S ANATOMY The Anatomical Basis of Clinical Practice, 40th ed. London: Elsevier, p.1450. [ull $\underline{T e x t]}$

16. Erol K, Karahan AY, Kerimoğlu Ü, Ordahan B, Tekin L, Şahin M, et al. An important cause of pes planus: the posterior tibial tendon dysfunction. Clinics and practice. 2015 Jan;5(1):11-3. [PubMed | Full Text | DOI]

17. Apley AG. Flat foot. Postgraduate medical journal. 1954 May;30(343):241. [Full Text | DOI]

This work is licensed under a Creative Commons Attribution 4.0 International License. The images or other third party material in this article are included in the article's Creative Commons license, unless indicated otherwise in the credit line; if the material is not included under the Creative Commons license, users will need to obtain permission from the license holder to reproduce the material. To view a copy of this license, visit http://creativecommons.org/licenses/by/4.0/ 